\title{
Growth Response of Chlorella vulgaris to Cultivation on Different Cassava Waste Mixtures
}

\author{
Nwankwo UN*, Agwa OK \\ ${ }^{*}$ Department of Microbiology, University of Port Harcourt, Nigeria
}

*Corresponding author: E-mail: uchennanwanodi@gmail.com

Citation: Nwankwo UN, Agwa OK. Growth Response of Chlorella vulgaris to Cultivation on Different Cassava Waste Mixtures. Electronic J Biol, 15:3

Received: May 13, 2019; Accepted: September 18, 2019; Published: September 24, 2019

\section{Research Article}

\begin{abstract}
The environmental hazard caused by the indiscriminate and continuous dumping of cassava wastes to the environment has necessitated the need for their recycling into diverse biological products. This exploitation has harnessed their potential to serve as a microalgae feed stock for biomass generation. Proximate composition of the cassava wastes showed cassava peel: carbohydrate- $86.85 \%$, protein- $4.18 \%$, lipid $5.98 \%$ and cassava digestate Carbohydrate- $75 \%$, protein- $2.5 \%$, lipid- $7.0 \%$. Physiochemical contents of the cassava waste in $\mathrm{mg} /$ $\mathrm{ml}$ showed cassava waste water: $\mathrm{pH}-3.55$, DO6.17, BOD5-138.81, COD-246.50, TDS-912.70, Nitrate-13.41, Phosphate-21.42, Sulphate-15.69, Calcium-17.61 and magnesium-9.56. Cassava peel extracts showed: pH-3.58, DO-6.25, BOD5-141.82, COD-151.60, TDS-132.23, Nitrate-12.30, Phosphate-13.14, Sulphate-18.17, Calcium-10.44 and magnesium-13.30. The cassava waste mixtures were cultivated on Chlorella vulgaris stock culture at various concentration ratios for a retention period of 14 days at an ambient temperature and natural illumination. Optimum growth was obtained with 160:40 for all cassava waste mixtures at an Optical density of $670 \mathrm{~nm}$ yielding 1.595 (abs) for CP:CW and 1.416 (abs) for CW:CP. The growth rate of Chlorella vulgaris at CP:CW was favourable with 160:40 concentration which increased exponentially from the $2^{\text {nd }}$ to $4^{\text {th }}$ day, while that of CW:CP concentrations was favourable at 140:60. Maximum doubling time for all the cassava waste concentration was observed at the $6^{\text {th }}$ day while the minimum doubling time was observed on the $10^{\text {th }}$ day for CP:CW concentration of 100:100 and on the $8^{\text {th }}$ day for CW:CP concentration of 160:40. From the results obtained from this research, it can be deduced that a mixture of cassava peel water and cassava waste water will support the growth of the Chlorella vulgaris at various concentration mixture though optimal growth is observed at Concentration
\end{abstract}

160:40 thus the cultivation of Chlorella vulgaris on cassava waste can be exploited as a remedial measure in curbing the menace of indiscriminate dumping of cassava waste which has greatly constituted environmental nuisance.

Keywords: Cassava; Carbohydrate; Pollution; Diarrhea

\section{Introduction}

Nigeria is by far the largest cassava producing nation in the world. Nigeria cassava production is at least a third more than that of Brazil and has now doubled the production of Indonesia and Thailand [1]. Cassava is the cheapest source of carbohydrate in Nigeria presently [2]. Majority of the cassava tubers produced in Nigeria are processed into food such as gari, fufu and lafun, with little left for the industry. According to [3], after accounting for wastes, about $93 \%$ of Africa's cassava production in the mid-1990s was consumed as food, $6 \%$ used as animal feed while only $1 \%$ was used as industrial raw material. In Nigeria, of the 32 million tons of cassava produced in $2001,84 \%$ was consumed as food, while only $16 \%$ was utilized as industrial raw material [1]. Among the several foods that cassava is processed into gari is the most dominant hence it is the most commonly traded cassava product [2]. A study by Knipseheer [4] estimated that $70 \%$ of cassava produced in Nigeria is processed into gari which amounts to 34 million tons of the $\mathbf{4 5}$ million tons of cassava produced in Nigeria in 2008. The waste generated during cassava processing can be in solid or liquid form which are both harmful to the environment [5]. The solid waste are obtained from cassava peels while the liquid waste are obtained when the fermented parenchyma mash are squeezed out [6]. These cassava peel wastes are aimlessly released into the earth and amassed as waste dumps in zones where cassava is processed. Cassava effluents are normally discarded beyond the area it is being processed, they flow freely into the environment there by settling in shallow 
depressions [7]. They are absorbed by the subsoil through infiltration into different water sources such as oceans, rivers, streams and other ground water sources hence polluting them $[7,8]$. Eutrophication and pollution can also occur during runoff by heavy rain fall because nutrients are being carried to the ground water without treatment [9]. The consumption of this polluted water by domestic animals and humans can cause serious health challenge resulting in diseases like diarrhea and stomach pain.

Its effects on plant vegetation can be noticed by the presence of yellowing of the leaves and stunted growth [10]. For a cassava effluent to be considered as a pollutant, it depends on the amount of some of the physiochemical parameters such as amount of Dissolved Oxygen (DO) needed to oxidize the organic matter, the Chemical Oxygen Demand (COD) and the Biochemical Oxygen Demand (BOD) which is the amount of oxygen necessary to stabilize the organic matter by microorganisms and enzymes [11]. Toxic compounds that have been found to be harmful to living organisms at toxic concentrations have also been seen preventing plant germination and growth especially in cereal plant. For instance, Cassava effluent have been observed to be responsible for inhibiting the germination of all types of cereal seed, the length of radicle and plumule of seedling shave been seen to decrease significantly with increase in effluent concentration [12]. These effects on cereal plants could be because cassava effluent in the fresh form contains cyanide, which is extremely toxic to humans and animals [13]. Biological degradation of cassava waste and sewage are hampered by the presence of cyanide which is an acidic component [14]. Cyanide have been found to form acidic complexes called hydrogen cyanide acid with zinc and hydrogen which constitutes a major threat to the environment [15]. Because of the possible effects on health and environment, the presence of simple and complex cyanide and their breakdown products such as cyanohydrins and hydrogen cyanide are becoming a great concern [16]. Microalgae are photosynthetic organisms which are capable of fixing $\mathrm{CO}_{2}$ while utilizing solar energy with proficiency of $10-15$ times more than that of a terrestrial plant, and produced more biomass for biofuel production [17]. To successfully replace the use of fossil fuel, microalgae have been seen as a veritable tool that can be exploited [18]. High starch and less lipid content have been found in some species of microalgae as reserve polymers. Microalgae biomass are important in anaerobic digestion during anaerobic biotransformation because it has high lipids, sugar and proteins content, and it does not contain recalcitrant lignin [19]. The potential of Chlorella vulgaris to produce $37 \%$ dry weight of starch makes it to be considered as a rising feedstock for bioethanol production [20]. Micro algae can lead to the production of lipids, protein and starch from photosynthetic processes that utilize light and nutrients. The relative measures of these metabolic segments are solidly associated with natural and supplement conditions including: the sum and power of day light; $\mathrm{CO}_{2}$ levels; $\mathrm{pH}$; temperature; accessible supplements; and, the appearance (or non-appearance) of organisms. The biochemical composition of the micro algal cells and their metabolism are adversely affected by environmental conditions such as light, temperature, $\mathrm{pH}$, presence of poisonous metals, availability of macro nutrients and non-mineral nutrients, [21]. Generally, these elements can influence photosynthesis; adjusting carbon fixation and sequestration in the environment thus are used during biofuel generation. The growth rate of micro algae will be fundamentally expanded at suitable conditions to generate more biomass [22]. Waste water has been treated through the use of Chlorella vulgaris as one of the most essential micro algae. Agwa et al. [23] recorded the growth of Chlorella vulgaris on cassava waste. Luz et al. [24] recorded the consumption of ammonium and phosphorus particles from manufactured waste water by Chlorella vulgaris. The growth of Chlorella pyrenoidosa in waste water from cassava ethanol fermentation has been reported to by Yang et al. [25] while the development of Chlorella minutissima in the municipal waste water for biofuel generation was considered by Ashish et al. [26]. These research works has demonstrated that the microalgae had high growth rate in cassava waste water and their development profoundly relied on the cultivation methods and growth conditions therefore the need to optimize micro algal growth conditions arises. This work is aimed at comparing the growth of Chlorella vulgaris from different concentration ratio of cassava waste and estimating the specific growth rate and doubling time of the microalgae.

\section{Materials and Methods}

\subsection{Sample collection}

The substrate used for this experiment are cassava peel and cassava waste water which were collected from cassava processing factory in Egberu-Ndoki area of Oyigbo, LGA Riversstate. An electric blender was used to blend the cassava peel into powdery form at a particulate size of $80 / 100$ mesh after it has been washed and sundried. The microalgae stock culture were collected from pond water at African Regional Aquaculture Center(ARAC) in Aluu, Rivers state and enriched in a synthetic medium containing $\mathrm{KNO}_{3}-0.132 \mathrm{~g}, \mathrm{Na}_{2} \mathrm{SiO}_{2}-0.066 \mathrm{~g}, \mathrm{Na}_{2}\left(\mathrm{PO}_{4}\right)_{2}-0.066 \mathrm{~g}$, EDTA-0.066 $\mathrm{g}$ in one litre of water for 7 days [23]. 


\subsection{Proximate analysis of the cassava waste}

Proximate analysis of the different chemical properties of the ground cassava peel was carried to determine major components such as Moisture content, Ash content, Crude fibre, Carbohydrate content, Protein content and Lipid content [23].

\subsection{Physiochemical properties of the cassava waste}

The physiochemical analysis of the ground cassava peel and the cassava waste water was estimated and compared to the FEPA standards for waste. The major component analyzed include; Nitrate content, Sulphate content, Phosphate content, Biological Oxygen Demand (BOD), Chemical Oxygen Demand (COD), Total Dissolved Solid (TDS), Dissolved Oxygen(DO), Calcium content, Magnesium content and $\mathrm{pH}$. Calcium and magnesium content were determined using Titrimetric method by EIMahi et al. [27]. Phosphorus content was estimated using Olsen's method. Nitrate, Sulphate and TDS were among those determined according to the standard methods of APHA [28]. pH was estimated using HANNA electronic pocket $\mathrm{pH}$ meter while BOD and $\mathrm{DO}$ were determined according to the procedures of Agwa et al. [29].

\subsection{Sample preparation}

The Cassava peels were sun dried, ground into fine powder using a Panasonic electric blender, model (MX-J110P) to obtain a cassava peel with particle size of $80 / 100$ mesh. Extracts were prepared by dissolving $10 \mathrm{~g}$ of ground cassava peels in $100 \mathrm{ml}$ of distilled water as described by Pothiraj et al. [30] and sterilized to destroy the pathogens and filtered using whatman's filter paper (No 1) while the cassava effluent were collected, sterilized and filtered.

\subsection{Experimental studies}

Growth selection of Chlorella vulgaris on cassava waste was monitored by cultivating the microalgae in cassava peel waste water; cassava waste water and on a mixture of the cassava peel water and cassava waste water (CP:CW). Five different concentration ratios of 180:20,160:40,140:6 $0,120: 80,100: 100$ labelled A-J respectively of the cassava wastes were used. Growth parameters were monitored at optical density of $670 \mathrm{~nm}$ for 14 days using $10 \%$ inoculum size. A positive control of Chlorella vulgaris cultivated on a novel synthetic medium was labeled $\mathrm{K}$ while a negative control of a cassava waste mixture without inoculation of Chlorella vulgaris was labeled $L$.

\section{Analyses}

\subsection{Optical density}

The Optical Density (OD) was determined using a spectrophotometer (Spectronic721 model) set at 670 $\mathrm{nm}$. About $5 \mathrm{ml}$ of the growing culture were removed aseptically, placed in the cuvette after blanking and the absorbance was measured at $670 \mathrm{~nm}$.

\subsection{Growth rate and doubling time}

The specific growth rate was determined using the formula derived by Huang et al.

$$
\begin{aligned}
& \mathrm{K}=(\text { LogODt-LogOD0 }) / t^{\star} 3.322[31] \mathrm{G}=0.301 / \mathrm{K}[32] \\
& \text { Where } \mathrm{K}=\text { Growth rate } \\
& \mathrm{G}=\text { Doubling time }
\end{aligned}
$$

\subsection{Cell dry weight of the microalgae}

The cell dry weight of Chlorella vulgaris was estimated from the linear equation of between optical density $\mathrm{OD}_{670}$ and the cell dry weight at a linear fitting coefficient $R^{2}=0.9894$.

Cell dry weight $(\mathrm{mg} / \mathrm{ml})=0.2070 D_{670}+0.0022$ [33].

\subsection{Chlorophyll a content}

The chlorophyll a content was estimated from the method of Su et al. [34] and absorbance reading was taking at optical density $\mathrm{OD}_{670}$. The amount of chlorophyll was calculated using the formula adopted by Surendhiran et al. [35].

$$
\text { Chlorophyll a }(\mathrm{mg} / \mathrm{L})=13.43 \times \mathrm{OD}_{670}
$$

\subsection{Biomass concentration}

The biomass concentration was mathematically derived from the equation of Dillschneider and Posten, 2013.

Biomass concentration $\mathrm{Cx}=0.376 \mathrm{~g} / \mathrm{L} \times \mathrm{OD}_{670}$ Statistical Analysis

The Statistical Package for the Social Sciences (SPSS) was used to calculate the mean and Standard Deviation (SD). The Post hoc test (Scheffe and Duncan) was used to test for the significant difference at $p$-values $\leq 0.05$ within the groups measured at $95 \%$ confidence level.

\section{Results and Discussion}

The results of the proximate analysis of the cassava waste samples proved that the cassava waste samples were capable of supporting micro algal growth based its carbohydrate, protein and lipid content as revealed on Table 1 . The results obtained 
Table 1: Proximate composition of cassava peel and cassava effluent.

\begin{tabular}{|c|c|c|}
\hline Digestate parameter (\%) & Cassava peel & Cassava effluent digestate \\
\hline Carbohydrate & $86.85 \pm 0.60^{* a}$ & $75.00 \pm 0.001^{* b}$ \\
\hline Lipid & $5.98 \pm 0.03^{* a}$ & $7.00 \pm 0.10^{* a}$ \\
\hline Protein & $4.18 \pm 0.03^{* a}$ & $2.50 \pm 0.05^{* b}$ \\
\hline Ash & $1.78 \pm 0.03^{* a}$ & $4.16 \pm 0.05^{* a}$ \\
\hline Fibre & $0.67 \pm 0.05^{* a}$ & $1.22 \pm 0.12^{* b}$ \\
\hline
\end{tabular}

were higher than that of Agwa et al. [23] and Uzodinma et al. [36] but was however similar to what was reported by Christi [37] as well as the report of Sarkiyayi et al. [38].

The physiochemical parameters of the cassava waste as compared to FEPA standards for waste showed that the wastes are reach in Nitrate, Phosphates and Sulphates which are necessary for stimulating microalgal growth [39]. The superscripts a and $\mathrm{b}$ are used to indicate statistical significance of the parameters. If same alphabets occur in a given row, the parameters are statistically insignificant to the study.

The physicochemical parameters of the Cassava Peel Extract (CPE) and Cassava Waste Water (CWW) in comparison to FEPA standards for waste showed that Dissolved Oxygen (DO), Biological Oxygen Demand (BOD) and Phosphate had values that exceeded that of the standards while the $\mathrm{pH}$, Calcium, Magnesium, Sulphate, Nitrate and Chemical Oxygen Demand (COD) had values that were lower than that of the standards though the Total Dissolved Solid (TDS) of the cassava waste water exceeded that of standard. The Phosphate content was far below what was reported by Agwa et al. [23]. The pH, calcium and magnesium content were lower than what was reported by Adejumo et al. [11].

Evidence of micro algal growth when optical density readings were collected at $670 \mathrm{~nm}$ absorbance for the cassava waste mixtures for 14 days was noticed as shown on Figure 1 and Figure 2. The results showed a steady increase in growth and the growth curve showed no lag phase throughout the period during which growth was monitored though there was a decline on day 4 for CW:CP mixture at 200:200 concentration but growth continued afterwards. Maximum growth was recorded at concentration mixture of 160:40 for CP:CW and CW:CP though the CP:CW mixture had higher growth than $\mathrm{CW}: \mathrm{CP}$ mixture probably because the cassava waste water had very high Total Dissolved Solids (TDS) which could have hindered micro algal growth, it could also be as a result

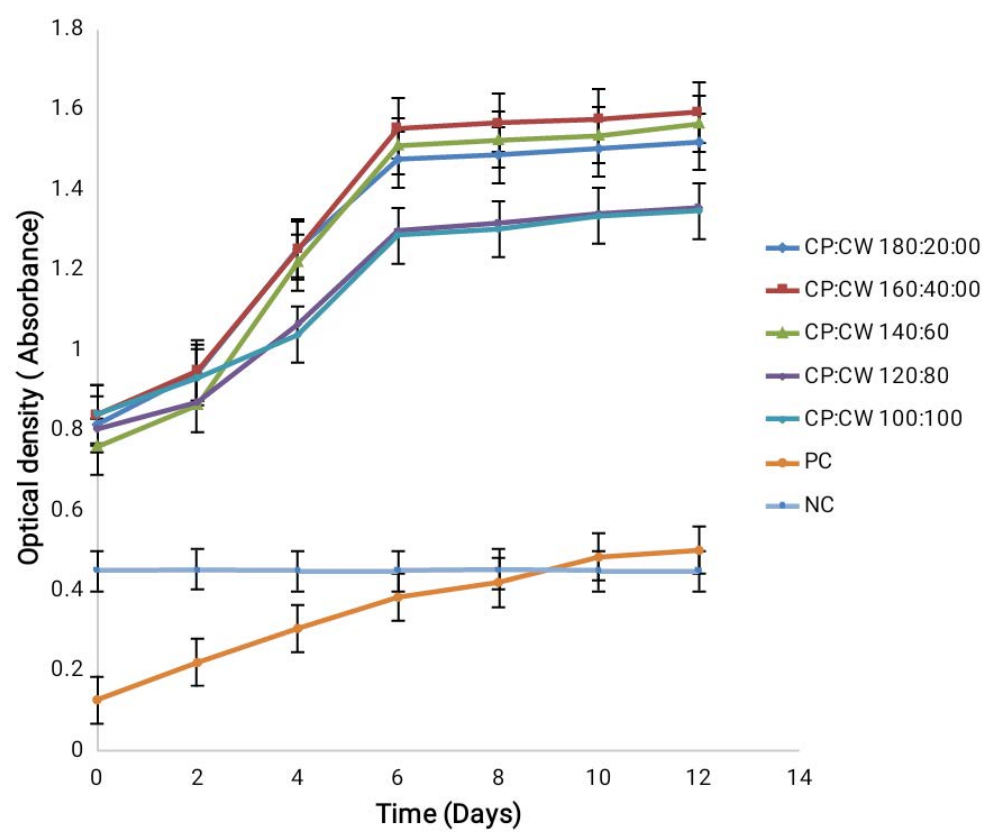

Figure 1: Changes in optical density with time of Cholrella vulgaris obtained from various ratio of cassava peel water and cassava waste water during the optimization period. 


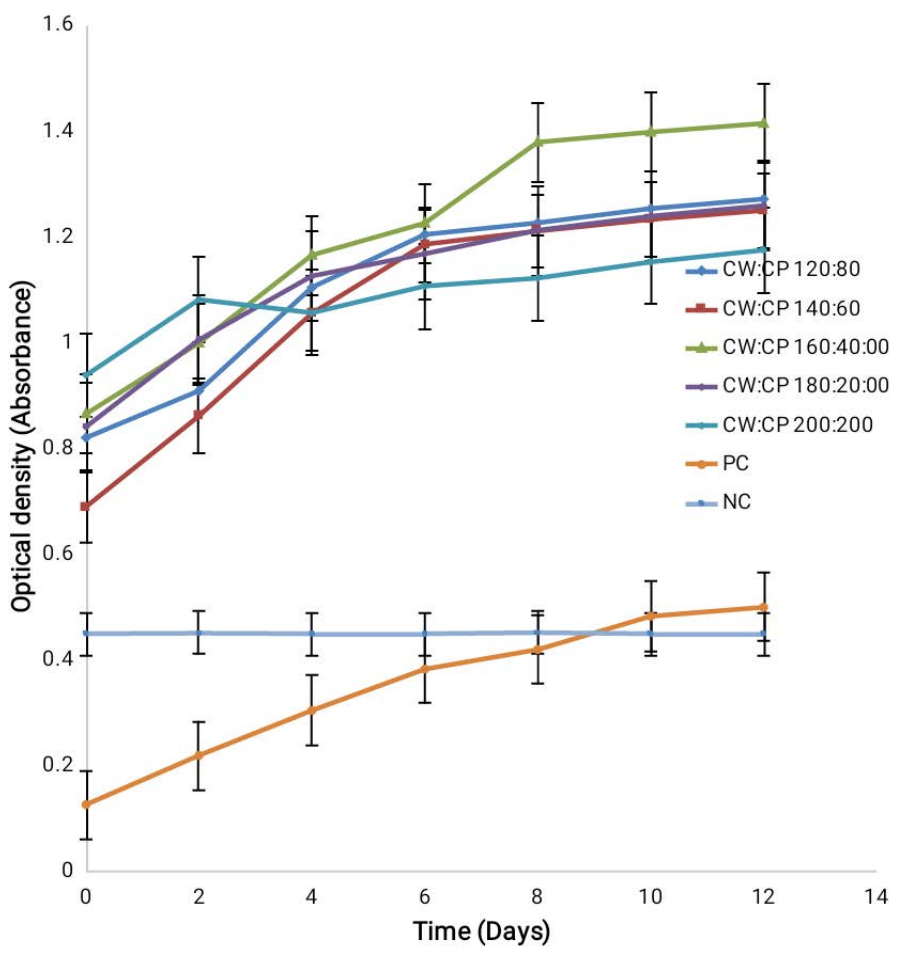

Figure 2: Changes in optical density with time of Cholrella vulgaris obtained from various ratio of cassava peel water and cassava waste water during the optimization period.

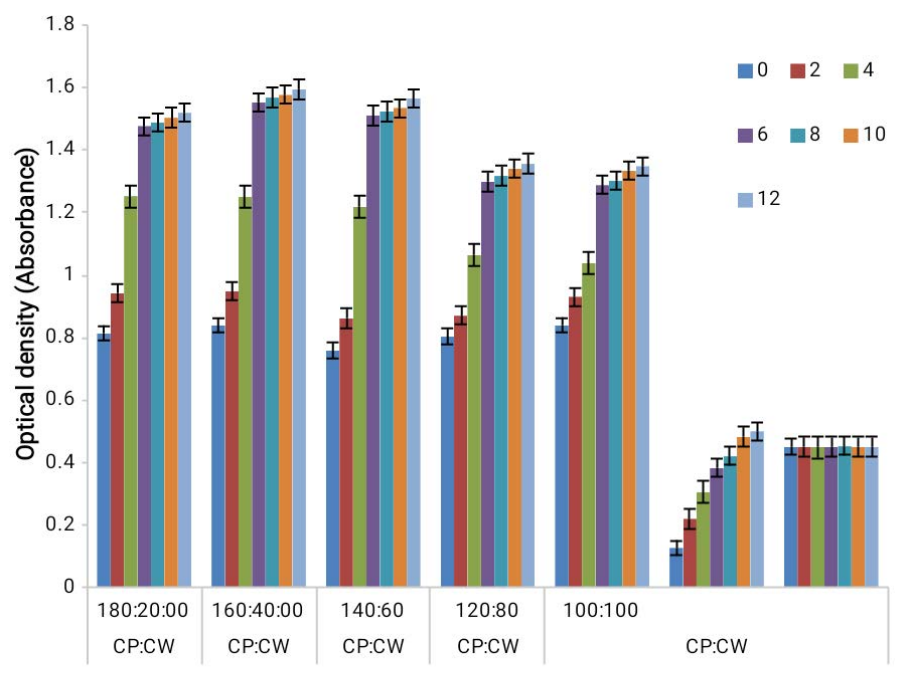

Ratio of $\mathrm{CP}$ and $\mathrm{CW}(\mathrm{ml})$

Figure 3: Changes in optical density of Cholrella vulgaris obtained from various ratio of cassava peel water and cassava waste water during the optimization period.

of cyanide concentration in the cassava waste water which has been reported to inhibit microbial growth [14]. This result supported earlier work by Agwa et al. [23] on Chlorella vulgaris is cultivation on cassava waste. Minimum growth was observed at $\mathrm{CP}: \mathrm{CW}$ mixture of 100:100 and CW:CP mixture of 200:200.

Chlorella vulgaris response to growth when cultivated on the various cassava waste mixtures for the different days when growth was monitored reveals that Chlorella vulgaris had a steady growth for the entire period it was cultivated on the cassava waste because of the availability of nutrients that supported its growth on cassava waste as shown on Figure 3 and Figure 4. It also shows that Chlorella vulgaris cultivated on novel synthetic medium did not grow as much as it did on cassava waste thus supporting the fact that Chlorella vulgaris cultivation on cassava waste is a very good media for micro algal cultivation.

The growth rate and doubling time of Chlorella vulgaris during its cultivation on various cassava waste mixtures areas represented in Figure 5 and Figure 6. 


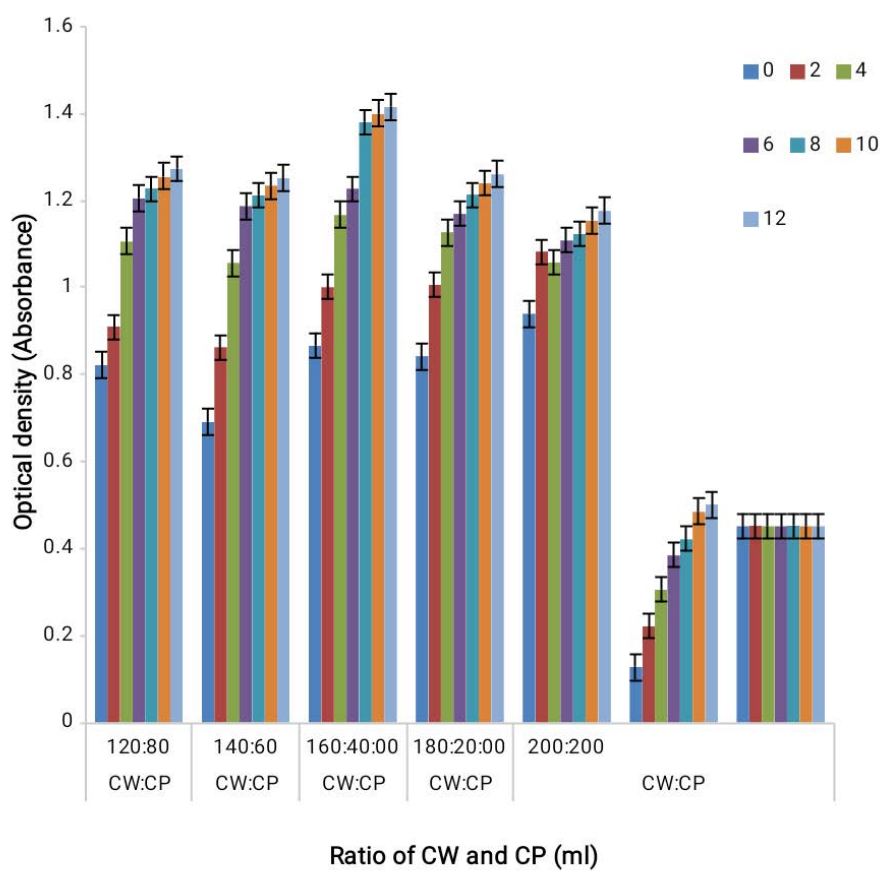

Figure 4: Changes in optical density of Cholrella vulgaris obtained from various ratio of cassava waste water and cassava peel water during the optimization period.

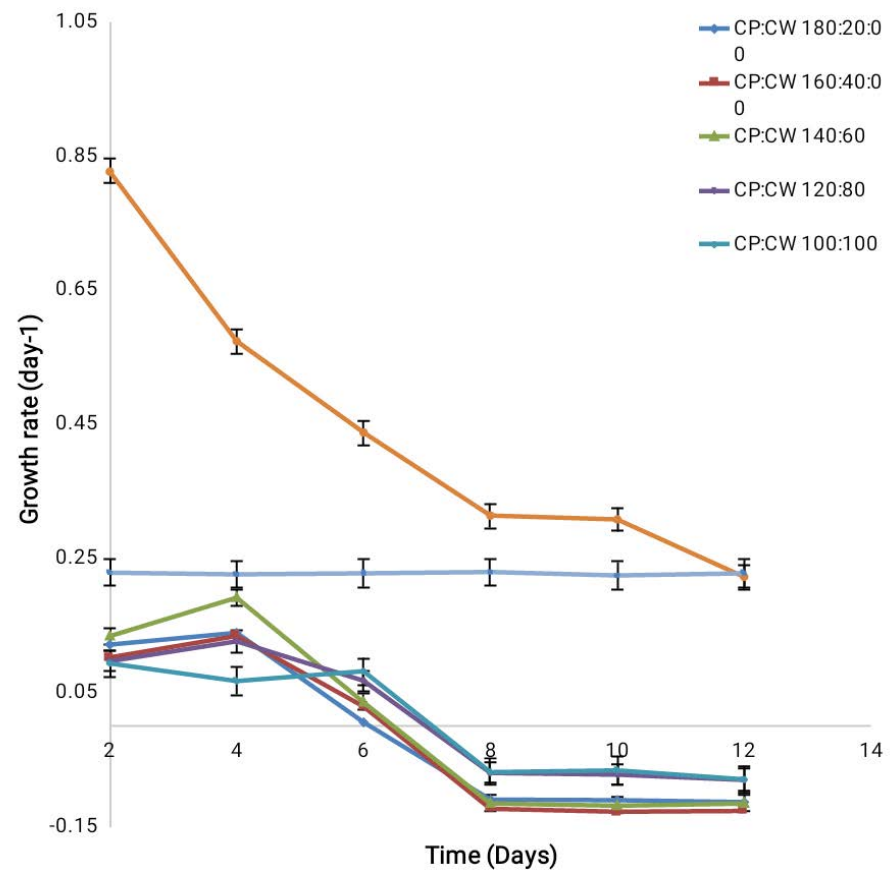

Figure 5: Changes in growth rate with time of Cholrella vulgaris obtained from various ratio of cassava peel water and cassava waste water during the optimization period.

From the result, it can be deduced that there was a steady decline in the growth rate of all the cassava waste mixtures (CP:CW) from day 0 to 8 before it entered a lag phase for the remaining days of cultivation. This decline in the growth rate could be as a result of nutrient depletion with increase in days because more micro algal cells are produced thus resulting in competition for available nutrients and space. From day 8 when the growth rate stopped declining, it may be that some metabolites released by the microalgal cells are serving as another source of nutrient to the micro algal cells.

This assumption is hinged on the fact that the positive control containing Chlorella vulgaris cultivated on novel synthetic media had a steady decline in the growth rate from day 0 to day 8 , a short static growth phase at day 8 to 10 before finally terminating its growth. This is however not so for CW:CP of 160:40 concentration where the growth rate stopped declining from 10 days. 


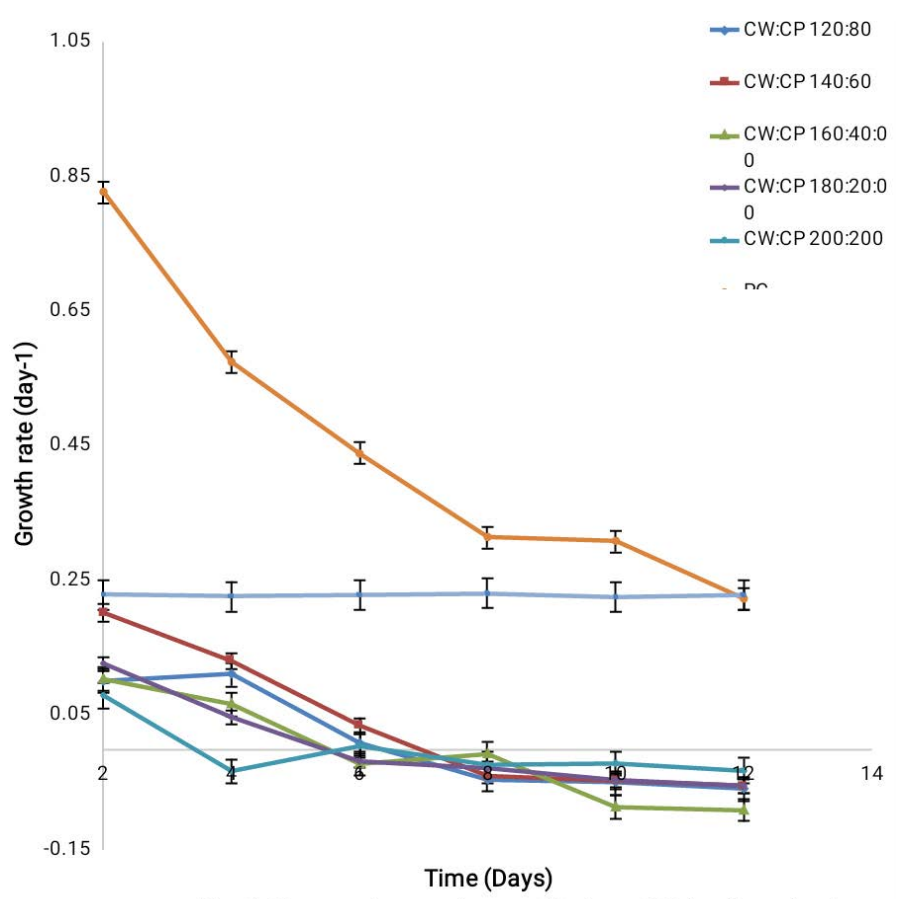

Figure 6: Changes in growth rate with time of Cholrella vulgaris obtained from various ratio of cassava peel water and cassava waste water during the optimization period.

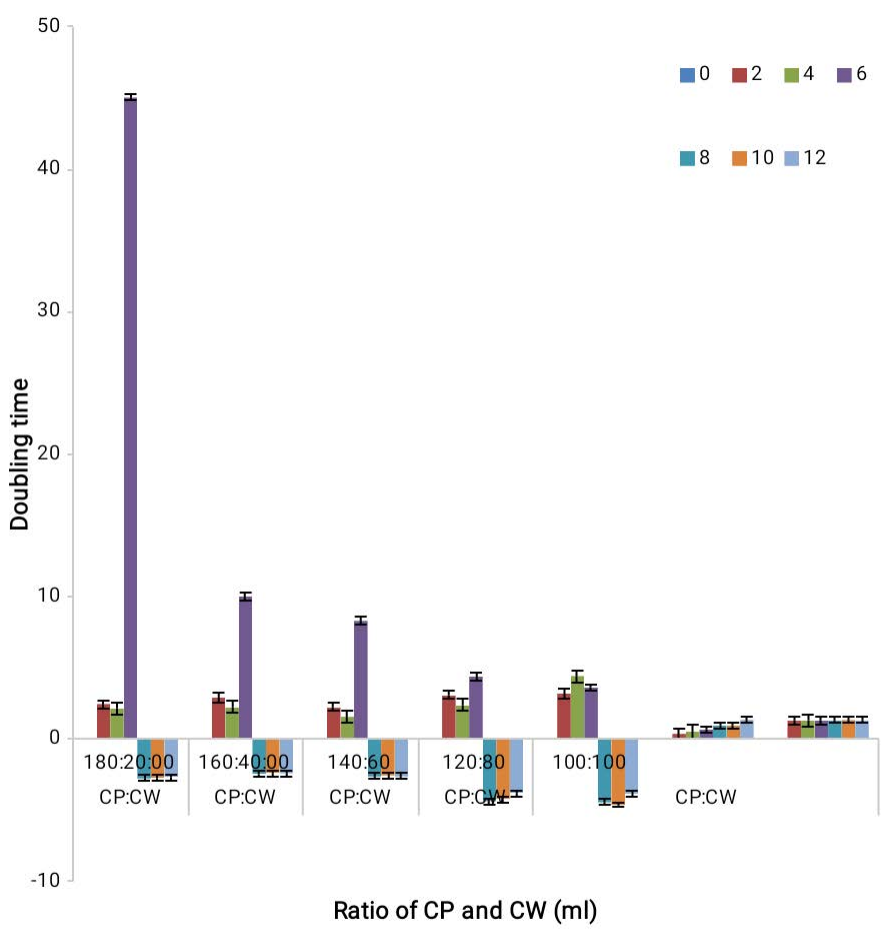

Figure 7: Changes in doubling time of Cholrella vulgaris obtained from various ratio of cassava peel water and cassava waste water during the optimization period.

The doubling time of the different cassava waste mixtures is shown on Figure 7 and Figure 8. It shows that maximum doubling time was recorded on the $6^{\text {th }}$ day at 180:20 for CP:CW concentration mixtures and it kept decreasing for all the concentrations while doubling time was maximum at 200:200 for CW:CP and minimum at $160: 40$ on the $8^{\text {th }}$ day. It also showed that at concentration ratio of 180:20, 160:40 and 140:60, growth was stationary implying that the micro algal cell were not growing from day 8 which could be because of the production of metabolites (Tables 2-8).

The Post Hoc test (Scheffe and Duncan) showed a significant difference for optical density, growth rate, doubling time, cell dry weight, chlorophyll content and biomass concentration of the microalgae between the cassava peels and effluent within the group measured at $95 \%$ confidence level ( $p$-values $<0.05$ ). 


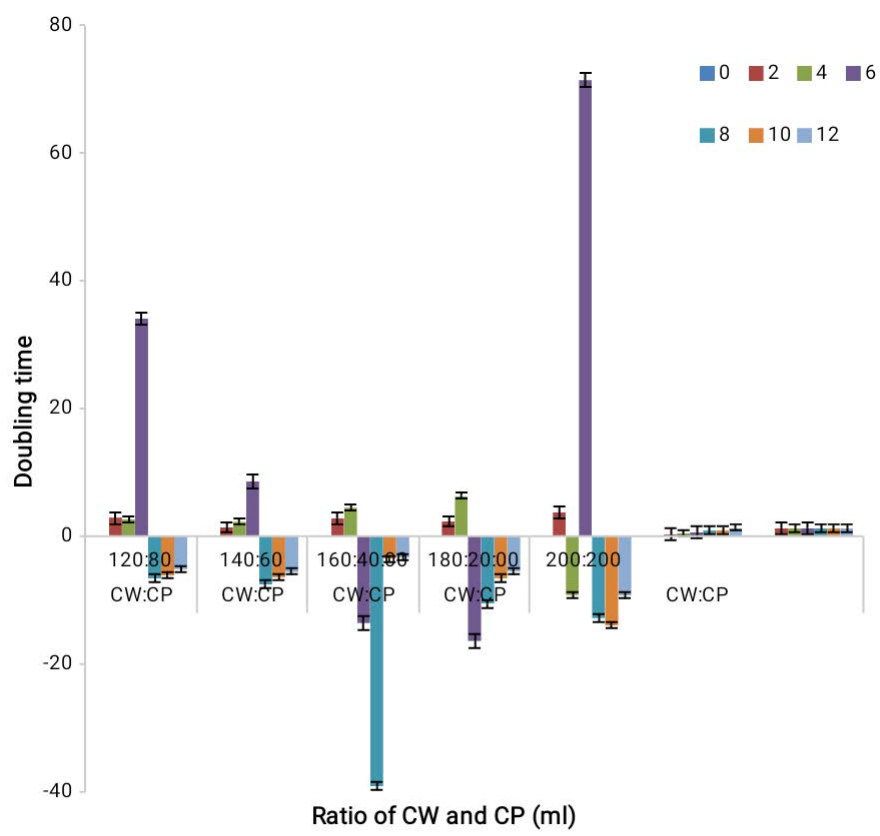

Figure 8: Changes in doubling time of Cholrella vulgaris obtained from various ratio of cassava peel water and cassava waste water during the optimization period.

Table 2: Physiochemical composition of cassava waste.

\begin{tabular}{|c|c|c|c|}
\hline Parameter $(\mathbf{m g} / \mathbf{m l})$ & CWW & CPE & *FEPA \\
\hline pH & $3.55 \pm 0.04^{* a}$ & $3.38 \pm 0.01^{* a}$ & 6 \\
\hline DO & $6.17 \pm 0.03^{* a}$ & $6.25 \pm 0.01^{* a}$ & 4 \\
\hline BOD5 & $138.81 \pm 0.11^{* a}$ & $141.82 \pm 0.01^{* a}$ & 50 \\
\hline COD & $246.50 \pm 0.36^{* a}$ & $151.60 \pm 9.50^{*}$ b & 430 \\
\hline TDS & $912.70 \pm 0.32^{* a}$ & $132.23 \pm 0.25^{*}$ b & 500 \\
\hline Nitrate & $13.41 \pm 0.20^{* a}$ & $12.30 \pm 0.14^{* b}$ & 20 \\
\hline Phosphate & $21.42 \pm 0.17^{* a}$ & $13.14 \pm 0.14^{* b}$ & 5 \\
\hline Sulphate & $15.69 \pm 0.41^{* a}$ & $18.17 \pm 0.10^{*}$ & 500 \\
\hline Calcium & $17.61 \pm 0.31^{* a}$ & $10.44 \pm 0.24^{*}$ b & 200 \\
\hline Magnessium & $9.56 \pm 0.12^{* a}$ & $13.30 \pm 0.17^{* b}$ & 200 \\
\hline
\end{tabular}

Means \pm Standard Error; superscripts with the same alphabet in a given row are statistically insignificant at $p \leq 0.05$; a and ${ }^{\mathrm{b}}$ : used to indicate statistical significance of the parameters.

Table 3. Cell dry weight of CP:CW mixture.

\begin{tabular}{|c|c|c|c|c|c|}
\hline & CP:CW & CP:CW & CP:CW & CP:CW & CP:CW \\
\hline & $180: 20: 00$ & $160: 40: 00$ & $140: 60$ & $120: 80$ & $100: 100$ \\
\hline 0 & 0.170905 & 0.175977 & 0.159313 & 0.168525 & 0.176184 \\
\hline 2 & 0.197505 & 0.19854 & 0.180841 & 0.182394 & 0.194917 \\
\hline 4 & 0.261571 & 0.261054 & 0.254533 & 0.222552 & 0.21717 \\
\hline 6 & 0.307939 & 0.323775 & 0.314874 & 0.271093 & 0.268816 \\
\hline 10 & 0.310216 & 0.326776 & 0.317668 & 0.274923 & 0.271818 \\
\hline 12 & 0.313425 & 0.328536 & 0.319945 & 0.279787 & 0.278545 \\
\hline & 0.316737 & 0.332365 & 0.326155 & 0.282892 & 0.28134 \\
\hline
\end{tabular}


Table 4. Cell dry weight of CW:CW mixture.

\begin{tabular}{|c|c|c|c|c|c|}
\hline & CW:CP & CW:CP & CW:CP & CW:CP & CW:CP \\
\hline & $120: 80$ & $140: 60$ & $160: 40: 00$ & $180: 20: 00$ & $200: 200$ \\
\hline 0 & 0.172251 & 0.145237 & 0.181566 & 0.176494 & 0.196677 \\
\hline 2 & 0.19057 & 0.180738 & 0.209304 & 0.210546 & 0.226278 \\
\hline 4 & 0.231039 & 0.220896 & 0.243666 & 0.235489 & 0.221103 \\
\hline 6 & 0.251739 & 0.247909 & 0.256189 & 0.244183 & 0.231556 \\
\hline 10 & 0.256293 & 0.253084 & 0.28786 & 0.253395 & 0.234661 \\
\hline 12 & 0.261882 & 0.257638 & 0.291793 & 0.25888 & 0.240975 \\
\hline & 0.265608 & 0.261157 & 0.295209 & 0.26302 & 0.245632 \\
\hline
\end{tabular}

Table 5. Chlorophyll a content of cassava waste mixture CP:CW.

\begin{tabular}{|c|c|c|c|c|c|}
\hline & $\mathbf{C P}: \mathbf{C W}$ & $\mathbf{C P}: \mathbf{C W}$ & $\mathbf{C P}: \mathbf{C W}$ & $\mathbf{C P : C W}$ & $\mathbf{C P : C W}$ \\
\hline & $180: 20: 00$ & $160: 40: 00$ & $140: 60$ & $120: 80$ & $100: 100$ \\
\hline 0 & 10.94545 & 11.27449 & 10.19337 & 10.79101 & 11.28792 \\
\hline 2 & 12.67121 & 12.73836 & 11.59009 & 11.69082 & 12.50333 \\
\hline 4 & 16.82779 & 16.79422 & 16.37117 & 14.29624 & 13.94706 \\
\hline 6 & 19.83611 & 20.86351 & 20.28602 & 17.44557 & 17.29784 \\
\hline 8 & 19.98384 & 21.05824 & 20.46732 & 17.69403 & 17.49258 \\
\hline 10 & 20.19201 & 21.1724 & 20.61505 & 18.00963 & 17.92905 \\
\hline 12 & 20.40689 & 21.42085 & 21.01795 & 18.21108 & 18.11036 \\
\hline
\end{tabular}

Table 6. Chlorophyll a content of cassava waste mixture CW:CP.

\begin{tabular}{|c|c|c|c|c|c|}
\hline & $\mathbf{C W : C P}$ & $\mathbf{C W : C P}$ & $\mathbf{C W : C P}$ & $\mathbf{C W : C P}$ & $\mathbf{C W : C P}$ \\
\hline & $120: 80$ & $140: 60$ & $160: 40: 00$ & $180: 20: 00$ & $200: 200$ \\
\hline 0 & 11.03275 & 9.28013 & 11.6371 & 11.3086 & 12.61749 \\
\hline 2 & 12.2213 & 11.58338 & 13.43672 & 13.5173 & 14.53798 \\
\hline 4 & 14.84687 & 14.1888 & 15.6661 & 15.13561 & 14.20223 \\
\hline 6 & 16.18987 & 15.94141 & 16.47861 & 15.69967 & 14.88044 \\
\hline 10 & 16.48533 & 16.27716 & 18.5334 & 16.29731 & 15.08189 \\
\hline 12 & 16.84794 & 16.57262 & 18.78857 & 16.6532 & 15.49151 \\
\hline & 17.08968 & 16.80093 & 19.01017 & 16.9218 & 15.79368 \\
\hline
\end{tabular}

Table 7. Biomass concentration of cassava waste mixtures $\mathrm{CP}: \mathrm{CW}$.

\begin{tabular}{|c|c|c|c|c|c|}
\hline & CP:CW & CP:CW & CP:CW & CP:CW & CP:CW \\
\hline & $180: 20: 00$ & $160: 40: 00$ & $140: 60$ & $120: 80$ & $100: 100$ \\
\hline 0 & 0.30644 & 0.317331 & 0.285384 & 0.302116 & 0.316028 \\
\hline 2 & 0.354756 & 0.358533 & 0.324488 & 0.32738 & 0.350056 \\
\hline 4 & 0.471128 & 0.472689 & 0.458344 & 0.400252 & 0.390476 \\
\hline 6 & 0.555352 & 0.587223 & 0.567948 & 0.488424 & 0.484288 \\
\hline 8 & 0.559488 & 0.59274 & 0.573024 & 0.49538 & 0.48974 \\
\hline 10 & 0.565316 & 0.595917 & 0.57716 & 0.504216 & 0.50196 \\
\hline 12 & 0.571332 & 0.60291 & 0.58844 & 0.509856 & 0.507036 \\
\hline
\end{tabular}

Table 8. Biomass concentration of cassava waste mixtures $\mathrm{CW}: \mathrm{CP}$.

\begin{tabular}{|c|c|c|c|c|c|}
\hline & $\mathbf{C W : C P}$ & $\mathbf{C W : C P}$ & $\mathbf{C W : C P}$ & $\mathbf{C W : C P}$ & $\mathbf{C W : C P}$ \\
\hline & $120: 80$ & $140: 60$ & $160: 40: 00$ & $180: 20: 00$ & $200: 200$ \\
\hline 0 & 0.308884 & 0.259816 & 0.32584 & 0.316592 & 0.353252 \\
\hline 2 & 0.34216 & 0.3243 & 0.376188 & 0.378444 & 0.40702 \\
\hline 4 & 0.415668 & 0.397244 & 0.43864 & 0.423752 & 0.39762 \\
\hline 6 & 0.453268 & 0.446312 & 0.461352 & 0.439544 & 0.41668 \\
\hline 8 & 0.46154 & 0.455712 & 0.51888 & 0.456276 & 0.422248 \\
\hline 10 & 0.471692 & 0.463984 & 0.526024 & 0.46624 & 0.433716 \\
\hline 12 & 0.47846 & 0.470376 & 0.532228 & 0.47376 & 0.442176 \\
\hline
\end{tabular}




\section{Conclusion}

From this study, it is evident that high micro algal growth as well as biomass production can be anticipated when Chlorella vulgaris is cultivated on cassava waste mixtures than when it is cultivated on a novel synthetic medium. The cassava peels proved to be a better substrate than the effluent due to its unique features as revealed in the proximate and physiochemical compositions. The growth rate and doubling time revealed that the cassava waste mixtures contained enough nutrients that supported growth during the cultivation of Chlorella vulgaris on the cassava waste. However, the microalgae through their photosynthetic machinery, were able to convert both wastes into organic macromolecules (carbohydrate, lipids, and proteins) stored in the cell as biomass as shown in the chlorophyll content, biomass concentration and cell dry weight values. Through the process of photosynthesis, the microalgae was able to convert carbon (iv) oxide, water and light into biomass in the form of carbohydrate in its cell wall (mainly in the form of cellulose and soluble polysaccharide) and plastids (mainly in the form of starch) which are potentially used as carbon sources for fermentation. The accumulation of carbohydrate in Chlorella vulgaris is due its carbon (iv) oxide fixation during the photosynthetic process which is a biological process that utilizes ATP/NADPH to fix and convert carbon (iv) oxide captured from air to produce glucose and other sugars through the Calvin cycle metabolic pathway. Microalgae are considered a promising feedstock for biofuel production such as ethanol, butanol, hydrogen and methane because they possess cellulose based cell wall with accumulated starch as the main carbohydrate source. The study supported earlier reports who reported that cassava wastes can be used in the cultivation of microalgae for biomass generation which can be utilized in lipid production thus serving as a precursor for biodiesel production through trans esterification reactions.

\section{References}

[1] Phillips TP, Taylor DS, Sanni L et al. (2004). A cassava industrial revolution in Nigeria; the potential for a new industrial crop. The Global Cassava Development Strategy. IFAD/FAO, Rome.

[2] Ohimain IE, Silas-Olu DJ, Zipamoh J. (2013). Biowaste generation by small cassava processing centers in wilberforce island Bayelsa State, Nigeria. J Environ Managt Public Safety. 2:051-059.

[3] Nweke FI,Spencer DSC, Lynam JK. (2002). The Cassava Transformation: Africa's best kept secret. Michigan State University Press, East Lansing, USA.

[4] Knipscheer H, Ezedinma C, Kormawa P, et al. (2007). Opportunities in the industrial cassava market in Nigeria. International Institute for Tropical Agriculture,
Ibadan, Nigeria.

[5] Cumbana AE, Mirione JC, Bradbury JH. (2007). Reduction of cyanide content of cassava flour in Mozambique by wetting method. Food Chemist. 101:894-897.

[6] Oboh G. (2006). Nutrient enrichment of cassava peels using a mixed culture of Saccharomyces cerevisae and Lactobacillus spp. solid media fermentation techniques. Elect J Biotech. 9:46-49.

[7] Ehiagbonare JE, Adjarhore RY, Enabulele SA. (2009). Effect of cassava effluent on Okada natural water. African J Biotechnol. 8:2816-2818.

[8] Morenikeji OA. (2010). The final hurdle to be crossed in the eradication of Dracunculiasis in Nigeria. American Sci. 6:76-81.

[9] Eze JI. (2010). Converting Cassava (Manihot spp) waste from Gari processing Industry to energy and biofertilizer. Global Res in Eng. 10:113-117.

[10] Ogundola AF, Laiasu MO. (2007). Herbicidal effects of effluent from processed cassava on growth performance of Chromolana odorata weeds population. African J Biotechnol. 6:685-690.

[11] Adejumo BA, Ola FA. (2008). Appraisal of local food packaging materials in Nigeria. Continen J Eng Sci. 3:13-20.

[12] Olorunfemi DI, Emoefe EO, Okiemen FE. (2007). Effect of cassava processing effluent on seeding height, biomass and chlorophyll contenton some cereals. Department of Botany, University of Benin. Res J Envi Sci. 2:221-227.

[13] Eggleston G, Bokanga M, Jean YW. (1992). Traditional African methods for cassava processing and utilization and research needs. In: Akoroda $\mathrm{MO}$ and Arene $\mathrm{OB}$ (Eds.), Proceedings $4^{\text {th }}$ Triennial Symposium, International Society for Tropical Root Crops, Africa Branch, Kinshasa, Zaire. December 5-8, 1989.

[14] Olayiwola G, Ukponmwan O, Olawode D. (2013). Sedative and anxiolytic effects of the extracts of Starchytarpheta cayennensisinmice. African J Trad Complement Alter Med. 10:568-579.

[15] Atulegwu PU, Egwuonwu N. (2011). Quality assessment of the Cassava-mill-effluent polluted soil. Res J Environ Sci. 5:342-353.

[16] Okunade DA, Adekalu KO. (2013). Physicochemical analysis of contaminated water resources due to cassava waste water effluent disposal. European Int J Sci Technol. 2: 75-84.

[17] Khan. (2009). Prospects of biodiesel production from microalgae in India. New Delhi. India. Renew Sust Energy Rev. 13:2361-2372.

[18] Miao X, Wu QY. (2006). Biodiesel Production from Heterotrophic Microalgae Oil. Biores Tech. 97:841-846.

[19] Posten C, Schaub G. (2009). Microalgae and terrestrial biomass as source for fuels-a process view. J Biotechnol. 142:64-69.

[20] Jasim MS, Maysam AM. (2014). Bioethanol production from green algae Chlorella vulgaris under different 
concentration of nitrogen. Asian J Natural App Sci. 3:27-36.

[21] Fábregas J, Maseda A, Domínguez A et al. (2004). The cell composition of Nannochloropsis sp. changes under different radiances in semi continuous Culture. World J Microbiol Biotechnol. 20:31-35.

[22] Zeng Y, Ji XJ, Lian M, et al. (2011). Development of a temperature shift strategy for efficient hexaenoic acid production by a marine fungoid protist, Schizochytrium sp. HX-308. App Biochem Biotechnol.164:249-255.

[23] Agwa OK, Neboh HA, Ossai-Chidi LN, et al. (2014). Cultivation of microalgal using cassava waste as a growth media. J Algal Biomass Utili. 5:8-19.

[24] Luz ED, Manuel M, Juan PH, et al.(2002). Removal of ammonium and phosphorus ions from synthetic wastewater by the microalgae Chlorella vulgaris coimmobilizsed in alginate beads with the microalgae growth-promoting bacterium Azospirillum brasilense. Water Res. 36:2941-2948.

[25] Yang CF, Ding ZY, Zhang KC. (2008). Growth of Chlorella pyrenoidosa in wastewater from cassava ethanol fermentation. World J Microbiol Biotechnol. 24:2919-2925.

[26] Ashish B, Monica B, Senthil C. et al. (2010). Chlorella minutissima-a promising fuel alga for cultivation in municipal waste waters. Appl Biochem Biotechnol. 161:523-536.

[27] EIMahi YE, Ibrahim IS, Abdel HM, et al.(1987). A simple method for evaluation of calcium and magnesium carbonates in soil. Soil Sci American J. 51:1152-1155.

[28] APHA. (1998). Standard methods for the examination of water and waste water. American Public Health Asso. 874.

[29] Agwa OK, Ibe SN, Abu GO. (2012a). Biomass and lipid production of fresh water algae Chlorella sp. using locally formulated media. Int Res J Microbiol. 3:285288.

[30] Pothiraj C, Arun A, Eyini M. (2015). Simultaneous saccharification and fermentation of cassava waste for ethanol production. Biofuel Res J. 2:196-202.

[31] Huang C, Zhang X, Lin Q, et al. (2002a). Studies on the $\mathrm{N}$ and $\mathrm{P}$ nutrient demand in Nannochlorisoculata. Marine Sci (China). 26:13-17.

[32] Huang C, Zhang X, Lin Q, et al. (2002b). Studies on the Ecology Factors of Oocystisborgei. J Zhan Jiang Ocean Univer. 22:8-12.

[33] Zheng J, Hao JM, Wang B, et al. (2011). Bioremediation of aquiculture wastewater by microalgae Isochrysiszhan jiangensis and production of the biomass material. Key Energy Mater. 61:491-495.

[34] Su CH, Fu CC, Chang YC, et al. (2008). Simultanous estimation of chlorophyll and lipid contents in microalgae by three-colour analysis. Biotechnol Bioeng. 99:1034-1039.

[35] Surendhiran D, Vijay M. (2012). Microalgae biodiesela comprehensive review on the potential and alternative biofuel. Res J Chem Sci. 2:71-82.

[36] Uzodinma EO, Ofoefule AU. (2009). Biogas production from blends of field grass with some animal waste. Int J Phys Sci. 4: 091-095.

[37] Christi Y. (2007). Biodiesel from microalgae. Biotechnol Advan. 25:294-306.

[38] Sarkiyayi S, Agar TM. (2010). Comparative analysis on the nutritional and anti- nutritional contents of the sweet and bitter cassava varieties. Adv J Food Sci Technol. 2:328-334.

[39] Anaga A, Abu GO. (2006). A laboratory scale cultivation of Chlorella and Spirulina using waste effluents from a fertilizer company in Nigeria. Biores Technol. 58:93-95. 